\title{
L'HOMME L'Homme
}

$180 \mid 2006$

Rendre visible

\section{Noël Jouenne, La Vie collective des habitants du Corbusier}

Paris, L'Harmattan, 2005, 160 p., bibl., fig., tabl. (« Questions contemporaines »).

\section{Gilles Teissonnières}

\section{(2) OpenEdition}

Journals

Édition électronique

URL : http://journals.openedition.org//homme/2586

DOI : $10.4000 /$ /homme.2586

ISSN : 1953-8103

Éditeur

Éditions de l'EHESS

Édition imprimée

Date de publication : 1 décembre 2006

Pagination : 247-248

ISSN : 0439-4216

Référence électronique

Gilles Teissonnières, « Noël Jouenne, La Vie collective des habitants du Corbusier », L'Homme [En ligne], 180 | 2006, mis en ligne le 25 octobre 2006, consulté le 24 septembre 2020. URL : http:// journals.openedition.org//homme/2586; DOI : https://doi.org/10.4000//homme.2586

Ce document a été généré automatiquement le 24 septembre 2020.

(c) École des hautes études en sciences sociales 


\title{
Noël Jouenne, La Vie collective des habitants du Corbusier
}

\author{
Paris, L'Harmattan, 2005, 160 p., bibl., fig., tabl. (« Questions \\ contemporaines »).
}

\section{Gilles Teissonnières}

1 PARMI LES quatre " unités d'habitation de grandeur conforme » - UHGC - réalisées en France et conçues par Charles-Édouard Jeanneret-Gris dit Le Corbusier ${ }^{1}$, c'est sur celle de Firminy (en Haute-Loire) que l'ethnologue Noël Jouenne a porté son attention. C'est l'un des intérêts de cet ouvrage que d'avoir placé au centre de cette recherche un lieu à propos duquel peu d'écrits existent.

2 Adoptant une démarche ethnologique, l'auteur a effectué une enquête de terrain durant un an et demi. Muni de son appareil photographique et de son carnet de terrain, il a arpenté les « rues » de l'unité d'habitation. S'appuyant sur des observations in situ et sur des entretiens avec les résidents $d u$ «Corbu », il a cherché à rendre compte de la mémoire du lieu, de son histoire et des pratiques qui y sont associées. Les nombreux ouvrages existants sur Le Corbusier ont alimenté sa réflexion et permis de mettre en perspective son travail.

3 Au-delà d'une terminologie - «cellule», " rue », " Modulor », etc. - qui informe sur l'originalité architecturale du projet «lecorbusien», résider dans une unité d'habitation conçue par cet architecte, c'est habiter un ensemble collectif remarquable qui allie les éléments naturels, le ciment et l'acier et, selon les termes mêmes de l'architecte, le « soleil, l'espace, la verdure ».

4 L'auteur retrace le contexte historique, l'évolution de l'unité d'habitation de Firminy et son originalité (pp. 17-35). Sur une échelle diachronique, Noël Jouenne s’intéresse à ce lieu en ce qu'il cristallise les enjeux politiques, architecturaux et sociaux dans un territoire à reconstruire au sortir de la Seconde Guerre mondiale. À cette époque, l'état de l'habitat en France et l'existence de bidonvilles imposent une reconstruction, et, dans ce contexte, Firminy fait l'objet d'une urbanisation accélérée. La construction de l'unité d'habitation au début des années 1960 s'inscrit dans un programme «d'urbanisation complète d'une ville “délabrée”»(p.18). Dès lors, cette ville sert de 
« laboratoire » pour le réaménagement de l'espace, qui néglige les conséquences de la rapidité de ces transformations pour la population locale.

5 L'histoire de l'unité d'habitation de Firminy est tout autant liée au contexte politique qu'aux passions déclenchées par la personnalité de Le Corbusier et par l'architecture qu'il promut. Dans ce sens, « l'existence du résident est [...] intimement liée à celle de l'architecture et de l'architecte» (p.11) et l'histoire du «Corbu» est jalonnée de moments « d'effervescence » politique et revendicative. C'est le cas au début des années 1970 quand l'unité d'habitation est « investie » par les « soixante-huitards » (p. 31).

Dans un second temps, l'ethnologue resitue la place du «Corbu » de Firminy au regard des multiples projets "lecorbusiens" d'unités d'habitations non menés à terme (pp.37-112). Il s'interroge sur les fonctions sociales de ce lieu relativement isolé spatialement, et montre qu'à la standardisation des conceptions architecturales de Le Corbusier répondent une appropriation et un réaménagement de l'espace des appartements par les locataires.

7 L'auteur met en évidence l'hétérogénéité des habitants du « Corbusier » qui décident de s'y installer autant par choix que par obligation. Il trace des portraits représentatifs de cette hétérogénéité où transparaissent néanmoins le caractère majoritairement éphémère du passage des habitants dans ce lieu en même temps qu'une forme d'attachement unanime à l'originalité architecturale et à la valeur patrimoniale de l'unité d'habitation. Parmi les habitants installés de longue date, il existe une mobilité à l'intérieur même de cette unité d'habitation. Noël Jouenne parle de "mutation" (pp. 65 sqq.) qui s'opère avec l'augmentation de la taille de la famille «et/ou des ressources financières ». Cette mobilité, favorisée par les vacances importantes d'appartements, est aussi conditionnée par l'architecture et "l'exiguïté des cellules » (p. 69). L'ethnologue s'intéresse à l'architecture du «Corbu » en ce qu'elle induit des modifications remarquables en terme de rapports de voisinage et, dans ce cas, comparées à d'autres immeubles collectifs, les nuisances sonores, par exemple, prennent une coloration spécifique.

8 Selon lui, la spécificité de l'architecture "lecorbusienne", attachée au renom de son concepteur (pp. 107 sqq.), soumise au principe du Modulor et considérant la place de l'enfant (pp. 96 sqq.) notamment, générerait une manière d'habiter le lieu et favoriserait « la sociabilité entre locataires » (p. 90). Mais l'isolement relatif de l'unité d'habitation concourrait aussi à l'établissement d'une solidarité ponctuelle reposant sur la constitution de réseaux de résidants. Si cette solidarité est observable dans d'autres quartiers de la ville, au "Corbu », elle se trouve sous-tendue par l'existence d'une association des locataires: douze clubs au début des années 1970, puis vingt-cinq dans les années 1980, autorisant, même si leur caractère s'avère parfois « confidentiel » voire privatif, une forme de lien intergénérationnel. Noël Jouenne s'attarde à comprendre les développement et fonctionnement de cette association. Il tente de décrypter les enjeux, notamment politiques, qui se tissent autour d'elle et met en évidence sa forte participation à «la construction de l'histoire» (p. 113) du lieu et sa contribution à l'établissement d'une "identité collective» (p.112) qui se cristallise autour de l'architecture et du projet «lecorbusien». Dans cette perspective, il s'intéresse aux autres initiatives des locataires et aux événements mineurs ou d'importance qui balisent l'histoire du lieu. C'est le cas, par exemple, de l'existence et de la disparition de l'école maternelle implantée sur la terrasse de l'édifice, 
" considérée par l'ensemble des habitants comme le cœur de l'unité d'habitation » (p. 134).

9 Cette recherche témoigne du souci constant de situer la place des individus au sein de cette cité HLM particulière et, plus largement, du projet de Le Corbusier. Elle questionne ainsi l'histoire et le devenir de ce site singulier classé aux monuments historiques.

\section{NOTES}

1.. Unité d'habitation dite "Cité Radieuse », Marseille, VIII ${ }^{e}$ arrondissement, 1952 ; unité d'habitation « Rezé », banlieue nantaise, 1955 ; unité d'habitation « Briey en Forêt », Meurthe-et-Moselle, 1963 ; unité d'habitation « Firminy-Vert », 1968. 